\title{
Recuperação dos territórios tradicionais guarani- kaiowá. Crónica das táticas e estratégias
}

\section{Tonico Benites}

\section{(2) OpenEdition \\ 12 Journals}

Edição electrónica

URL: https://journals.openedition.org/jsa/14022

DOI: $10.4000 /$ jsa. 14022

ISSN: 1957-7842

Editora

Société des américanistes

\section{Edição impressa}

Data de publição: 31 dezembro 2014

Paginação: 229-240

ISSN: 0037-9174

\section{Refêrencia eletrónica}

Tonico Benites, «Recuperação dos territórios tradicionais guarani-kaiowá. Crónica das táticas e estratégias », Journal de la Société des américanistes [En ligne], 100-2 | 2014, mis en ligne le 01 juillet 2015, consulté le 02 septembre 2022. URL : http://journals.openedition.org/jsa/14022 ; DOI : https:// doi.org/10.4000/jsa. 14022 


\section{CHRONIQUE DU GROUPE D'INFORMATION \\ SUR LES AMÉRINDIENS}

\section{RECUPERAÇÃO DOS TERRITÓRIOS TRADICIONAIS GUARANI-KAIOWÁ. CRÓNICA DAS TÁTICAS E ESTRATÉGIAS}

A presente crónica tem por objetivo explicitar o processo de reocupação e retomada (jeike jey) dos territórios tradicionais (tekoha guasu) efetuado pelas lideranças religiosas e políticas Guarani-Kaiowá. Articuladas em rede (ñemoiru ha pytyvõ) tal processo se desencadeou no seio da grande assembleia (Jeroky ha Aty Guasu) a partir de meados de 1970 no sul do atual Estado de Mato Grosso do Sul. Para uma melhor compreensão da história da reocupação dos territórios tradicionais feita pelos Guarani-Kaiowá, pretende-se, por um lado, descrever as situações históricas de colonização de seus territórios por parte do Estado brasileiro e, por outro, procura-se mostrar como se deu a organização e articulação das lideranças religiosas e políticas Guarani-Kaiowá para recuperar seus territórios tradicionais e reivindicar seu reconhecimento oficial por parte do Estado brasileiro.

Inicialmente, é importante destacar que tanto as memórias dos anciãos Guarani-Kaiowá transmitidas para as novas gerações quanto à documentação oficial do governo brasileiro, sobretudo através dos arquivos do Serviço de Proteção aos Índios (SPI), revelam uma presença indígena muito antiga na região dos rios Brilhante, Dourados, Apa, Amambai, Iguatemi, Mbarakay, Hovy e Pytã. Desta forma, os «territorios tradicionais » atualmente reocupados e reivindicados pelos Guarani-Kaiowá estão localizados nas margens destes rios.

\section{As SITUaÇões históricas de COLONIZaÇão ${ }^{1}$}

Antes de tudo, é fundamental compreender as diferenças e as nuanças entre as noções de tekoha* e de tekoha guasu* e por isso passo a explicitar a definição de cada uma dessas expressões. Tekoha, na visão indígena, significa um espaço territorial de domínio específico, muitas vezes, de uma liderança de uma família extensa (tey’i)*. Assim, tekoha é definido como o "lugar exclusivo de uma 
liderança de uma família onde ela pode realizar seu modo de ser - teko ». Por sua vez, tekoha guasu significa um espaço territorial muito mais amplo e de uso de várias famílias extensas e de várias lideranças religiosas e políticas. Tekoha guasu poderia ser entendido então como uma rede de tekoha que inclui diversos espaços compartilhados de caça, de pesca, de coleta, de habitação, de ritual religioso e festivo, constituindo-se como o palco das relações intercomunitárias de alianças políticas intercomunitárias e matrimoniais. Este espaço territorial muitas vezes é delimitado por micro-bacias hidrográficas. Dessa forma, a categoria de tekoha guasu é atualmente compreendida como um amplo território em rede e não apenas como pequenas ilhas de terras isoladas e delimitadas pelos órgãos indigenistas do Estado Brasileiro, como, por exemplo, as Reservas Indígenas criadas pelo SPI entre 1910 e 1930.

Até o final da segunda metade do século xx, diversas famílias extensas, aliadas entre elas, ainda habitavam em determinados lugares exclusivos aonde ainda havia recursos naturais, como rios e córregos para pescar e fontes d'águas para o consumo. Na proximidade das habitações indígenas, além de suas lavouras tradicionais, na floresta e no campo era possível encontrar caças, árvores frutíferas, plantas medicinais, mel, etc. Desta forma, até meado de 1930, várias famílias extensas Guarani-Kaiowá ainda viviam de modo autônomo nos seus tekoha e tekoha guasu antigos, onde não passavam miséria. Pertenciam exclusivamente a um lugar específico nas margens dos rios e se distanciavam de 15 a $20 \mathrm{~km}$ dos tekoha das outras famílias extensas com quem mantinham relações de troca.

As fontes documentais demonstram que o primeiro processo de retirada ou expulsão dos Guarani-Kaiowá de seus territórios iniciou-se com a política de povoamento e colonização da faixa de fronteira entre Brasil e Paraguai. Assim, a primeira «invasão » dos territórios Guarani-Kaiowá ocorreu, sobretudo, após a Guerra da Tríplice Aliança (1864-1870). Os documentos históricos evidenciam que a política oficial de povoamento da faixa de fronteira avançou, primeiramente, nos territórios indígenas.

No período subsequente à guerra, na década de 1880, o Estado brasileiro começou a abrir a região para o capital privado e concedeu uma enorme concessão de terras para a Cia. Matte-Larangeira, permitindo a ela a exploração exclusiva da erva-mate nativa na região em que estavam localizados os tekoha guasu dos indígenas. Com isso, iniciou-se uma nova forma de mediação com os Guarani-Kaiowá baseada, sobretudo, na mão-de-obra para o trabalho da extração da erva-mate. Até a década de 1920, mais ou menos, a empresa Cia. Matte-Laranjeira acabou protegendo involuntariamente os territórios GuaraniKaiowá, visto que como ela tinha o monopólio exclusivo da exploração da erva-mate ela impedia a penetração de outros colonos na região. Até a metade da segunda década do século xx, pode-se dizer que os Guarani-Kaiowá não sofreram significativas mudanças na ocupação dos seus territórios, uma vez que 
apenas os integrantes das famílias extensas eram engajados de forma periódica nos trabalhos de extração da erva-mate e posteriormente na derrubada das matas. Desta forma, puderam permanecer nos seus territórios tradicionais.

Foi somente a partir das décadas de 1950 e 1960 que teve início um novo período mais violento de retirada das famílias indígenas de suas habitações. Esse novo período é marcado tanto pelo fim do monopólio da Cia. Matte-Larangeiras quanto pelo aumento do loteamento da região quando se abre a região para a instalação de inúmeras fazendas privadas.

É importante lembrar, no entanto, que desde o ano de 1915 as primeiras Reservas Indígenas no atual Estado de Mato Grosso do Sul foram instituídas, pressionando os indígenas a se transferirem para o interior delas. Contudo, foi só a partir da década de 1970 que se assistiu ao maior processo de expropriação das terras de ocupação tradicional dos Guarani-Kaiowá, em favor de sua titulação privada. As terras indígenas foram consideradas como «terra devoluta» e « terra vazia » e por isso o território tradicional Guarani-Kaiowá se tornou objeto legal de comércio do Governo. Neste contexto histórico os GuaraniKaiowá foram progressivamente expulsos de seus territórios tradicionais. Dessa maneira, ao longo de boa parte do século xx, o governo brasileiro passou a comercializar os territórios tradicionais indígenas localizados no atual Cone Sul de Mato Grosso do Sul. Os compradores dessas terras começaram a explorar a mão de obra indígena e depois os expulsaram de suas habitações, passando a devastar a floresta e a construir fazendas sobre esses mesmos espaços.

Entre as décadas de 1950 e 1970, nessa operação histórica de expulsão dos Guarani-Kaiowá de seus territórios, envolveram-se os novos compradores das terras com agentes políticos locais, missionários e militares. Estes agentes passaram a operar com violência no atual sul de Mato Grosso do Sul e contaram também com a participação de funcionários dos órgãos indigenistas do Estado, como o antigo SPI e, posteriormente, a atual FUNAI.

Como ficou evidente, no início da segunda metade do século XX, o processo de colonização oficial do sul do atual Estado do Mato Grosso do Sul entrou numa nova fase e se intensificou bastante. Desta forma, inúmeras comunidades Guarani-Kaiowá começaram a ser expulsas de seus territórios antigos, tendo sido transferidas e confinadas nas oito Reservas Indígenas criadas entre 1915 e 1930 pelo SPI. Para o Governo, essas reservas eram consideradas como os únicos espaços oficiais destinados aos indígenas.

Por conta do processo histórico oficial de colonização dos territórios Guarani-Kaiowá aproximadamente quinze mil indígenas dos que hoje reivindicam seus tekoha guasu tradicionais encontram-se residindo ou nas margens das rodovias (BR) ou nas pequenas áreas reocupadas e retomadas. Além desses, aproximadamente trinta mil outros indígenas, ou seja, a maioria dos GuaraniKaiowá estão assentados nas oito Reservas Indígena se nas nove Terras Indígenas que foram oficialmente demarcadas respectivamente pelo SPI entre 1915 e 1930 e 
pela FUNAI a partir da década de 1980. É relevante considerar que o cone sul do Estado de Mato Grosso do Sul apresenta hoje a maior população indígena do Brasil. São aproximadamente quarenta e seis mil indivíduos, pertencentes às etnias Guarani e Kaiowá que estão distribuídas em áreas de tamanhos variados, boa parte delas em conflito, totalizando somente quarenta mil hectares de área em diferentes etapas de regularização fundiária (demarcadas, identificadas, em acampamentos aguardando reconhecimento do Estado, etc.) ${ }^{2}$

\section{A organização e articulação das lideranÇas religiosas e políticas}

Como ficará evidente no item subsequente foi exatamente diante desta situação fundiária complicada e conflituosa que se originaram desde o final da década de 1970 as primeiras iniciativas de articulação e luta de várias lideranças Guarani-Kaiowá para retornar aos seus antigos territórios. As narrações de várias lideranças religiosas e políticas evidenciam que a realização dos grandes rituais religiosos (jeroky guasu) e das grandes assembleia intercomunitárias (aty guasu)* foram e ainda são fundamentais para os líderes políticos e religiosos se envolverem nos processos de reocupação, retomada e recuperação de seus territórios tradicionais específicos.

Jeroky é o termo usado para se referir a um ritual religioso Guarani-Kaiowá, sendo que guasu significa grande. Neste sentido, o jeroky guasu pode ser traduzido por um grande ritual religioso coordenado por líderes religiosos (ñanderu)* que nesta ocasião entram em contato com os diversos deuses (ñanderungusu hyapua)* e guardiões (ñanderyke'y overava yvyjara)* de todos os seres localizados no cosmos Guarani-Kaiowá para buscar o apoio e a intervenção divina nos problemas enfrentados aqui na Terra. Desse modo, a realização dos jeroky guasu deve ser vista como um grande encontro entre líderes espirituais ( nanderu), seus auxiliares (yvyra'ija) e os demais indígenas (homens, mulheres, crianças, jovens). Tal encontro começou a ocorrer com mais periodicidade a partir dos anos 1970. É neste contexto ritual que emerge a força para lutar e que se elaboram as táticas e as estratégias para reocupar, retomar e recuperar os territórios tradicionais perdidos.

A expressão Aty significa « reunião » ou « encontro », sendo que guasu, como já dissemos, equivale à "grande ». Desta forma, Aty Guasu pode ser definido como uma grande assembleia ou encontro onde também se juntam muitas lideranças políticas e religiosas de diversas famílias extensas (tey’i). Trata-se de uma forma de articulação e organização política intercomunitária e interfamiliar de lideranças que compõe as famílias extensas dos diversos tekoha e tekoha guasu. Durante as assembleias Aty Guasu são discutidas e tomadas decisões importantes que afetam a todos, como decisões sobre a reocupação e recuperação de parte dos territórios tradicionais. Os Aty Guasu são pensados como o principal foro de 
discussão e de decisão política articulada entre as lideranças políticas e religiosas das famílias extensas Guarani-Kaiowá que pretendem reocupar e retomar os seus territórios tradicionais. Os Aty Guasu são realizados trimestralmente no interior dos territórios reocupados contando não somente com a participação dos moradores das áreas retomadas como também das lideranças organizadoras do Aty Guasu que vêm de diversas outras áreas indígenas do Mato Grosso do Sul. É fundamental destacar que a atuação e a valorização dos saberes dos ñanderu Guarani-Kaiowá foram e são sempre vitais nos processos de reocupação e recuperação de parte dos territórios tradicionais. Tal ação se dá através dos rituais religiosos (jeroky) realizados por eles.

Como ficou evidente, foi a partir da década de 1970 que as várias lideranças das famílias extensas expulsas de seus territórios, que viviam ou nas margens da estrada ou nas "reservas indígenas », começaram a se articular. Já ao longo de 1980 e 1990 começaram a reocupar e retomar seus primeiros territórios antigos com o claro objetivo de pressionar a identificação e regularização de outros espaços reivindicados. Essa situação de conflito perdura até os dias de hoje com grau extremo de violência.

As táticas de reocupação e retomada dos territórios tradicionais (Jeike Jey) são discutidas e deliberadas amplamente pelas lideranças religiosas e políticas organizadas através do Aty e Jeroky Guasu. A expressão Jeike* citada acima significa « entrar», " ocupar», " enfrentar» ou «afrontar». E Jey* tem o significado de « repetir », « ativar » novamente ou uma vez mais. Por essa razão o termo Jeike Jey é definido como uma resposta ou reação organizada através do Aty Guasu frente à expulsão violenta das famílias extensas de seus territórios, objetivando reocupar e recuperar esses territórios perdidos em favor dos fazendeiros. Dessa forma, Jeike Jey é sempre o resultado da articulação política e da luta religiosa de lideranças das famílias extensas para retornar aos seus antigos espaços territoriais. Jeike Jey envolve os líderes políticos e religiosos que participam dos grandes rituais religiosos e que são fundamentais para efetivar o processo de reocupação e retomada dos territórios perdidos. Jeike Jey também é visto como uma forma de resistência contra as violências dos fazendeiros, uma atuação permanente e insistente através da ação dos ñanderu durante os rituais religiosos. A ação dos líderes religiosos é vista como uma técnica de luta ou de guerra para que os indígenas tenham êxito nos processos de enfrentamento com os pistoleiros das fazendas, sobretudo no momento de entrada e retomada dos territórios tradicionais.

Os primeiros processos de reocupação e retomada dos territórios tradicionais ocorreram, de fato, a partir do final da década de 1970 e início da de 1980. Posteriormente, o movimento de reocupação continuou durante os anos 1990 sempre através de uma rede articulada de lideranças religiosas e políticas que estavam vinculadas ao Aty Guasu. O processo de reocupação e retomada das terras tradicionais na década de 1990 ocorreu em certos casos diante da demora 
na identificação, demarcação e homologação das Terras Indígenas pelo Governo Federal. Em outros casos, quando as terras já estavam identificadas e demarcadas, o processo de reocupação se dava pela judicialização do processo demarcatório que atrasava a devolução total e definitiva das terras Guarani-Kaiowá já identificadas e reconhecidas pelo Estado brasileiro.

Foi nesses contextos que se desencadeou a articulação das lideranças religiosas e políticas para reivindicar a regularização das terras tradicionais. Ao mesmo tempo, as lideranças religiosas (ñanderu) passaram a sagrar no seio da Jeroky ha Aty Guasu quais seriam as ações e táticas específicas de reocupação e retomada das terras, indicando e orientando as famílias envolvidas no processo de reocupação quais eram as formas mais seguras de atuar. Conforme os depoimentos dos indígenas envolvidos em diversas reocupações, as táticas que foram deliberadas pelo conjunto de ñanderu nos Aty Guasu realizados na década de 1970 foram postas em prática nas décadas de 1980, 1990 e 2000 e são válidas até os dias de hoje.

É importante compreender que todas as famílias extensas que foram expulsas de seus territórios tradicionais ao longo do século Xx apresentam uma vontade profunda de retornar ao seu tekoha antigo. Por isso as lideranças articuladoras das famílias extensas passaram a se interessar em participar dos rituais religiosos (jeroky) e dos Aty Guasu, uma vez que nestes espaços são socializados nomes, experiências e a localização de tekoha antigos que foram involuntariamente abandonados e que se pretende recuperar atualmente. Além disso, essas lideranças já se apresentam articuladas internamente nas Aty Guasu para fazer a reocupação de seus tekoha antigos, solicitando assim o apoio (ñomoiru ha pytyvõ)* de outras lideranças religiosas e políticas articuladoras do Aty Guasu. O significado da expressão ñomoiru ha pytyvõ é muito importante para se compreender a articulação dessas diversas lideranças. Ñomoiru* significa, por exemplo, "se articular», "se juntar em grupo", "se proteger», "ser companheiro (a)». A expressão Pytyvõ ${ }^{*}$ pode ser traduzida por «prestar apoio », « cooperar », " dar força », « encorajar », " escoltar », etc. Nesse sentido, Nomoiru ha Pytyvõ, é definido como uma série de táticas que são postas em prática no momento de reocupação e retorno aos territórios antigos. Ñomoiru ha Pytyvõ é o resultado de vários anos de articulação das lideranças religiosas e políticas no seio da Aty Guasu e do Jeroky Guasu.

\section{RitUAL RELIGIOSO E TERRITORIO}

Foi em 1979, durante a realização do primeiro grande ritual religioso (Jeroky Guasu) e da primeira grande assembléia (Aty Guasu), que começou o processo de articulação Ñomoiru ha Pytyvõ para a reocupação e retomada dos territórios tradicionais. Esse processo perdura até os dias de hoje. Nessas ocasiões e encontros específicos, os líderes religiosos explicam repetidamente que a 
realização simultânea de ritual religioso é fundamental para recuperar o diálogo com os seres invisíveis e os guardiões dos tekoha antigos. Estes seres são divindades supremas que pertencem ao cosmo (yvaga) Guarani-Kaiowá. Os ñanderu declararam que somente através do jeroky permanente é possível buscar essa comunicação, apoio e intervenção de seus parentes invisíveis e guardiões da terra, rio e floresta para recuperar e retomar os territórios tradicionais que foram abandonados por conta das expulsões. Além dessa exigência vital decretada durante os Aty e Jeroky Guasu desde os anos 1970, os líderes religiosos demandam rigorosamente a participação coordenada dos rezadores durante o processo de reocupação e retomada dos tekoha tradicionais. Por essa razão fundamental, o conjunto dos líderes religiosos (ñanderu) e de seus auxiliares estão sempre envolvidos em todas as ações de retomada.

Já durante a realização do primeiro Jeroky ha Aty Guasu no ano de 1979, as lideranças religiosas determinaram que durante o processo de reocupação dos tekoha antigos era necessária e fundamental à participação direta de todos os integrantes das famílias extensas envolvidas na retomada, incluindo as crianças, os homens, as mulheres e os idosos. Assim, a equipe de frente que coordena a reocupação de um território é sempre composta por rezadores e rezadoras, seus auxiliares, lideranças políticas, idosos e crianças. Dos integrantes dessa equipe de frente é exigida a participação permanente nos rituais religiosos durante vários meses. Esses rituais têm por objetivo principal proteger e preparar os envolvidos na reocupação para que elas mantenham bom contato com os seres invisíveis e os guardiões do tekoha abandonado, uma vez que eles irão manter novamente contatos com os seres visíveis e invisíveis existentes no lugar. Por isso, de quatro a cinco dias antes da efetivação da retomada todos os integrantes da equipe de frente devem obrigatoriamente participar do ritual religioso (jeroky) por um período de três ou quatro noites realizados em frente do altar sagrado ( $y v y r a$ ' $i$ Marangatu)*, molhando o centro da cabeça com água (yary)* feita com a casca e folha do cedro, planta nativa sagrada para os Guarani-Kaiowá. Esta cerimonia religiosa de batismo (mongarai)* serve para que os batizados sejam reconhecidos pelos seus antepassados e para que eles se protejam dos seres invisíveis e dos guardiões maléficos existentes no lugar. $\mathrm{Na}$ última noite, antes do grupo se deslocar em direção da área a ser retomada, os membros da equipe de frente devem se pintar ou tingir parte do corpo e do rosto de urucum (yruku)*. Pelo respeito e honra de seus antepassados, todos os homens devem segurar com força o arco e flecha e o porrete tingido (yvyra para) e jurar a reocupação do tekoha antigo. Durante as noites, normalmente durante toda a madrugada, os rezadores movimentam seus chocalhos (mbaracá) e as mulheres batem lentamente seus takuapu*, um pedaço do caule de taquara. Depois de quatro ou cinco dias de reza, na última noite, o rezador faz um discurso final no qual autoriza a partida dos envolvidos na reocupação da terra, dando orientações importantes para o êxito da empreitada. 
Depois de várias solicitações de reocupação de nossa terra através de nosso ritual jeroky, recebemos a ordem dos guardiões da terra do cosmo (yvaga)*, e por isso estamos voltando a nos encontrar com os nossos parentes mortos e enterrados lá em nosso tekoha antigo, que já se tornaram os seres invisíveis, com muita alegria, pelo respeito e honra aos nossos antepassados estamos voltando para morar e viver novamente no tekoha de nossos antepassados. Nós não podemos atacar com violência às pessoas, fazendeiros e $k a r a i^{*}$ ( «brancos ») que estão por lá. Nós não estamos indo para atacar e matar ninguém lá, mas sim, estamos voltando para reocupar com alegria o tekoha de nossos antepassados. Vamos voltar lá! E não é para recuar! Chegando lá, em primeiro lugar, vamos construir um altar sagrado, o yvyra’i Marangatu, e começaremos a realizar o ritual religioso jeroky, lá no lugar indicado que está na margem do córrego e no interior do restante da floresta. Esse primeiro ritual jeroky será feito lá, é para comunicar aos nossos antepassados e nossos guardiões que voltamos novamente para viver em nosso tekoha (Fala feita pelo ñanderu Atanásio Teixeira antes da retomada de Jaguapiré-memby, Município de Tacuru, Mato Grosso do Sul, 11/08/1996).

Importa destacar que a reocupação e a retomada dos territórios antigos sempre ocorre após a última noite de ritual religioso, sempre durante a madrugada. A narração desse líder religioso (ñanderu) evidencia que a equipe de frente é a responsável pela organização da saída do grupo de seu acampamento. Eles se deslocam a pé em direção da terra antiga indicada, sempre localizada a uma distância de 30 a $40 \mathrm{~km}$ da " reserva indígena » e da cidade mais próxima de onde os indígenas partem. No momento da partida cada integrante do grupo deve levar consigo seus pertences pessoais assim como alguns gêneros alimentícios, pedaço de lona para armar barraca e utensílios e instrumentos rituais de proteção. Conforme o depoimento de outra liderança " as longas caminhadas de nosso grupo até a terra antiga duraram de oito a dez horas de viagem ». Uma vez a entrada efetuada, os integrantes do grupo começam a caçar e pescar no interior do tekoha reocupado, buscando alimentação para os integrantes do grupo.

Ao analisar os depoimentos de diversas lideranças religiosas e politicas constata-se quea partir do final da década de 1970 até os dias de hoje as lideranças engajadas na retomada (ñemoiru ha pytyvõ) usam rigorosamenteas mesmas táticas que foram decretadas pelos ñanderu durante os primeiros Jeroky ha Aty Guasu da década de 1970. Com essas táticas e estratégias já foram reocupadas e retomadas mais de duas dezenas de territórios tradicionais. Todos os processos de reocupação desses tekoha antigos foram coordenados pelos líderes religiosos e políticos. Em todas as terras indígenas antigas reocupadas é construído um altar sagrado (yvyra'i Marangatu) pelos rezadores GuaraniKaiowá onde é realizado com frequência rituais religiosos (Jeroky) e assembléias (Aty Guasu).

Comojá foi dito antes, a partir de 1979 as lideranças articuladas, reivindicantes das terras tradicionais, começaram a se reunir trimestralmente nas Aty Guasu, 
buscando discutir e deliberar a respeito das reocupações e das retomadas. Ao mesmo tempo, no seio de cada Aty Guasu, os líderes e os articuladores políticos também começaram a elaborar documentos escritos e petições (kuatiañe'e)* destinadas ao governo e à justiça federal. Nestes documentos formulam por escrito as reivindicações, indicando a delimitação aproximada das terras antigas. Assim, uma das táticas mais recentes para pressionar o governo federal sobre a demarcação das terras antigas é a solicitação de audiências com autoridades federais em Brasília, capital do país. Nessas ocasiões são entregues vários documentos escritos (kuatiañe'e) às autoridades federais (presidente da FUNAI e ministro da justiça). Para isso, comitivas de lideranças religiosas e políticas se deslocam de Mato Grosso do Sul à Brasília. Essas viagens das lideranças indígenas à Brasília ocorrem esporadicamente, a cada seis meses. Em todas essas viagens também vão os líderes religiosos (ñanderu) que antes da audiência realizam os rituais religiosos no interior dos gabinetes das autoridades federais. Essa prática esporádica de viagem tem por objetivo cobrar e pressionar a demarcação dos territórios tradicionais.

É fundamental registrar que no seio da primeira Jeroky e Aty Guasu realizada no ano de 1979, os líderes religiosos determinaram que a realização do ritual religioso é imprescindível para tratar da recuperação das terras perdidas, visto que na concepção Guarani-Kaiowá o tekoha antigo, o rio e a floresta são compostos por seres visíveis, invisíveis e guardiões com quem os indígenas devem saber conviver em harmonia, de forma equilibrada, mantendo uma boa relação de diálogo e respeito mútuo para não serem prejudicados dentro das áreas retomadas. Tal interação dos indígenas com o território ocorre através desses rituais, permeados de cantos e rezas. Assim, a prática do ritual é obrigatória no processo de reocupação e retomada dos tekoha guasu antigos. Esse ritual religioso faz parte das táticas de reocupação, sempre coordenado pelo conjunto das lideranças religiosas, experientes ñanderu. Dessa forma, todos os integrantes Guarani-Kaiowá envolvidos na reocupação da terra devem participar com frequência desses rituais religiosos para se protegerem dos seres visíveis e invisíveis maléficos e ao mesmo tempo para manter uma boa relação com os espíritos guardiões de seus antepassados que fazem parte dos territórios tradicionais.

Por fim, é relevante observar que tanto as lideranças religiosas e políticas dos Jeroky ha Aty Guasu, quanto os integrantes das famílias extensas (crianças, mulheres, homens e idosos) dos territórios antigos já foram atacados e retirados com a violência pelos pistoleiros das fazendas e às vezes pelas autoridades policiais do Estado a mando da justiça. Porém, os indígenas expulsos e violentados voltam a reocupar e a retomar os seus territórios antigos. Além disso, nesse contexto de reocupação, desde a década de 1980, mais de duas dezenas de lideranças religiosas e políticas já foram assassinadas de modo cruel pelos pistoleiros contratados pelos donos das fazendas em decorrência do processo de 
conflito desencadeado pelas reocupações dos territórios tradicionais. Apesar dessas violências históricas exercidas contra os líderes indígenas e membros das famílias extensas articuladas dentro dos Aty guasu, as lideranças religiosas continuam realizando o ritual religioso (jeroky) e continuam articulando novos movimentos de reocupação e de retomada de seus territórios tradicionais.

Tonico Benites, Guarani-Kaiowá

Pós-doutorado,

Universidade Federal do Rio de Janeiro/Museu Naciona (RJ)

[tonicobenites2011@hotmail.com].

\section{Notes}

1. Les sous-titres sont le fait des éditeurs. Les astérisques indiquent les mots repris dans le bref glossaire ci-dessous.

2. Pour visualiser sur une carte les emplacements des territoires ici mentionnés, le site à consulter est le suivant $: \mathrm{http}: / /$ pib.socioambiental.org/pt/povo/guarani-kaiowa.

\section{Commentaire des Éditeurs}

Ce texte est intéressant à plusieurs titres.

Tout d'abord, l'auteur, Tonico Benites, est un Guarani-Kaiowá et un antropologue. C'est aussi un membre du mouvement indigène et indigéniste qui livre ici la version pédagogique divulguée à propos des procès de revendication des terres Guarani au sud du Brésil, écrivant en tant qu'un des leaders du mouvement de contestation, et producteur d'un discours « officiel» parce qu'adressé aux officiels brésiliens, ce qui donne une image des leviers employés : voir l'emphase sur la « religion », le fait que ces revendication soient liées à " la valorisation des savoirs des ñanderu Guarani-Kaiowá - leaders religieux -, nécessaires dans la constitution des processus de reoccupation d'une partie au moins des territoires traditionnels $\gg$.

Il s'agit par ailleurs véritablement d'une chronique, certes brève, mais qui traite l'historique de l'organisation des revendications des Guarani, et rend compte aussi de leur stratégie politique et de la mobilisation des pratiques, des croyances et des contraintes inscrites dans une tradition recomposée. Au-delà d'une récupération de terres, ce qui est en jeu c'est l'espoir de retrouver une vie sociale où puissent s'inscrire les noms, les expériences et la mémoire du passé.

En troisième lieu, ce texte paraît dans le Journal de la Société des américanistes car il y a urgence, une urgence consécutive aux événements récents. On pourra se reporter, pour apprécier cette situation à plusieurs sites, comme celui de Survival France (www.survivalfrance.org). La situation extrêmement grave dans laquelle se trouvent actuellement les Guarani Kaiowá ainsi que leurs parents Nhandeva 
dans la région du Mato Grosso do Sul justifie pleinement ce texte dont l'intérêt est d'offrir l'expression choisie pour que les revendications soient entendues par les Blancs, dans les termes qu'ils peuvent entendre, ce qui, d'un certain point de vue, nous renvoie cruellement à nous-mêmes.

Le « prophétisme tupi-guarani » (Clastres 1975), comme d'autres prophétismes dans le monde, apparaît ou réapparaît dans une situation de crise qui fait surgir le personnage du prophète porteur d'une vision d'avenir et d'espérances ; celles-ci incarnent la croyance en un monde nouveau tout en invoquant les temps anciens, les deux temporalités se référant à un monde meilleur, passé ou futur. Ces mouvements, souvent syncrétisme des enseignements missionnaires et de traditions autochtones, reposent toujours sur un profond sentiment religieux, dans le sens d'un ancrage des hommes sur un territoire où leur relation avec des entités spirituelles, qui l'occupaient et l'occupent, peut s'exercer. On ne peut lire le texte de Tonico Benites sans l'insérer dans ce contexte politico-religieux auquel il adhère avec la force de ceux qui luttent.

Nous remercions Gerald Taylor qui a aimablement fourni les explications des termes utilisés dans cet article à l'aide du dictionnaire de Cadogan (1992), ainsi que celui de Krivoshein de Canesse et Acosta Alcaraz (1997) : voir Glossaire ci-après.

\section{GLOSSAIRE}

aty

guasu

jeroky

jey

jeike

jeike jey

karai

kuatiañe'e

mongarai

ñanderu

ñanderu gusu hyapua groupe, ensemble, réunion ; aty guasu: grande assemblée, grande réunion

augmentatif, d'où « grand »

fête, célébration, danse, rituel ; jeroky guasu : grand cérémoniel ; jeroky ha aty guasu: grande réunion cérémonielle

revenir; de nouveau

je-ike : préfixe réfléchi ou impersonnel -entrer ; réoccupation nom donné aux Blancs « document écrit », vient de ñe'ë « parole, discours » et du nheengatu kwatiara « peint, gravé » mo-karai « rendre l'équivalent d'un Blanc, d'un Chrétien », vient de mo-karai causatif-Blanc, d'où « baptiser »

ñande-ru, avec le sens de « Notre Père » apparaît dans Cadogan avec le sens d'" Être suprême", « esprit»

hyapu signifierait « faire du bruit, résonner » 
ñadeyke'y overava yvyjara

overava

yvyjara

ñemoiru ha pytyvõ

takuapu

teko-ha

yary

yruku

yvyra'i marangatu

yvyra-para vient du terme autrefois utilisé ñande-ryke'y, dont le deuxième élément est la forme dépendante qui correspond à une forme indépendante tyke'y " frère aîné »

peut-être overáva « celui qui brille»?

$y v y$-jara « seigneur ou maître de la terre »

ñe-mo-irü se décompose ainsi : « réfléchi-factitifcompagnon " «se faire compagnon » et pytyvõ « aide, aider » d'où le sens de " s'entraider » vient de takua «bambou » (takwara en nheengatu) et/ou « un bruit très fort ». Il est intéressant de noter que des flûtes utilisées dans des rituels $\mathrm{du}$ Haut Xingu où vivent des groupes tupi, se nomment takwara

pluriel de teko qui signifie coutûme, mode de vie d'où son acception comme mode de vie attaché au territoire qui permet de vivre (écologie et liens aux esprits; d'où tekoha guasu: «territoire tribal»

« eau »

urucu (Bixa orellana)

autel de bois

plusieurs traductions : " nuancé », « de couleurs variées »

\section{RÉFÉRENCES BIBLIOGRAPHIQUES}

Cadogan Léon

1992 Diccionario Mbya-Guarani, Castellano, edición preparada por Friedl Grünberg, bajo la dirección de Bartomeu Melia, Fundación León Cadogan, Asunción.

Clastres Hélène

1975 La Terre sans Mal. Le prophétisme tupi-guarani, Éditions du Seuil, París.

Krivoshein de Canesse Natalia, Feliciano Acosta Alcaraz

$1997 \tilde{N} e^{\prime} \ddot{e r y r u}$. Diccionario guaraní-español, Instituto superior de lenguas, universidad nacional de Asunción (Ñemiyy), Asunción. 